\title{
The Neutrophil to Lymphocyte Ratio May Predict Benefit from Chemotherapy in Lung Cancer
}

\author{
Dan Liu ${ }^{a} \quad$ Jing Jin ${ }^{a} \quad$ Li Zhang $^{b}$ Lei Li $^{\mathrm{a}} \quad$ Juan Song ${ }^{\mathrm{a}} \quad$ Weimin Lia \\ aDepartment of Pulmonary \& Critical Care Medicine, West China Hospital, Sichuan University, Chengdu, \\ Sichuan Province, 'Lab of Pathology, West China Hospital, Sichuan University, Cheng Du, Sichuan \\ Province, P.R. China
}

\section{Key Words}

Neutrophil to lymphocyte ratio - Platelet to lymphocyte ratio $\bullet$ Lung cancer Inflammation • Prognosis

\begin{abstract}
Background/Aims: The objectives of this study were to evaluate the impact of the neutrophil to lymphocyte ratio (NLR) and platelet to lymphocyte ratio (PLR) on overall survival (OS) and to explore the value of changes in the NLR and PLR with treatment as a response indicator. Methods: A total of 934 patients were eligible for retrospective analysis between 2008 and 2014. The pretreatment and post-treatment PLR and NLR in all patients were calculated based on complete blood counts. Univariate and multivariate Cox regression analyses were performed to determine the associations of the PLR and NLR with OS. Results: The pretreatment NLR and PLR were correlated with different disease status and response to chemotherapy. Patients with lower NLR and PLR had a significantly better complete response (CR) rate to chemotherapy versus those with a higher NLR and PLR $(p<0.001)$. The NLR and PLR were sustained in patients who obtained a CR compared with moderate or poor response patients. The lower NLR of pretreatment was independently associated with a favourable prognosis in whole patients with lung cancer (HR: 0.69, 95\% CI, 0.55-0.85, p<0.001). In the patients under control after chemotherapy, the NLR of post-chemotherapy had a greater impact on survival, and the low NLR level maintained during chemotherapy was identified a predictor for favourable survival. PLR was not an independent prognostic indicator in the whole cohort or any subgroups. Conclusion: Our results suggested that NLR was well-connected with outcomes and response to chemotherapy in patients with lung cancer. As a response indicator, NLR may predict benefit from chemotherapy and improve patient selection.

Weimin Li M.D., Ph.D.

KARGER
Department of Pulmonary \& Critical Care Medicine

West China Hospital, Sichuan University, Chengdu 610041 (China)

Tel.+86-28-85423001. E-Mail weimi003@yahoo.com 


\section{Introduction}

Lung cancer is one of the most common tumours in the world, and its mortality accounts for $28 \%$ in males and $26 \%$ in females, ranking first in all cancers [1]. The main treatments for lung cancer are surgery and chemotherapy [2]. Although the treatments in lung cancer have made great progress, more effective treatment strategies must consider patient selection and evaluate the prognosis of patients with lung cancer.

Previous studies showed that cancer-related inflammation has been recognized as one of the markers of cancer with an essential role in the modulation of the tumour microenvironment $[3,4]$. Inflammation may play an important role in the tumour genesis process and progression by promoting cancer cell proliferation and survival, angiogenesis, and tumour metastasis, as well as impacting tumour response to systemic therapies [5]. Lymphocytes, which have been thought to play an essential role in cancer immune surveillance, are hypothesized to suppress tumour maturation [6]. In addition, the NLR and PLR are easily measured and repeatable markers, which may provide a simple and cheaper avenue for cancer-related inflammation. The imbalances in the ratio of NLR and PLR may provide insight into understanding tumour progression and prognosis in individuals with cancer [7]. These ratios have shown prognostic relevance across a large variety of tumour types [7-12]. In lung cancer, a number of retrospective studies have estimated the prognostic significance of baseline NLR and PLR [12-22].

However, those studies typically focused on specific types or specific populations with lung cancer. There are few studies evaluating the roles of the NLR and PLR in whole lung cancer cohorts with different subtypes and treatments. The prognostic value of different treatments and the association with response to treatment remain unclear.

The current study aimed to assess the prognostic roles of the NLR and PLR in patients with lung cancer during different treatment status. We also analysed the predictive value of pre/post-treatment NLRs and PLRs for response to chemotherapy.

\section{Materials and Methods}

\section{Participants}

Patients included in this dataset were hospitalized between January 2008 and Dec 2014. The inclusion criteria included the following: 1) diagnosed lung cancer by biopsy, and 2) data about complete blood count, blood chemistries and other inflammatory factors before and after different treatments. This study was approved by the Ethical Committee of West China Hospital of Sichuan University. All patients signed written informed consent before entering the study.

\section{Data collections and follow up}

Data were collected retrospectively from individual medical case notes, electronic patient records and pathology reports, including age, gender, histological subtype, stage, smoking status and therapy. Stage was determined according to the American Joint Committee on Cancer Staging System (AJCC), $7^{\text {th }}$ Edition [23]. The NLR was defined as the absolute neutrophil count divided by the absolute lymphocyte count, and the PLR referred to the absolute platelet count divided by the absolute lymphocyte count. Values of the pretreatment NLR and PLR were measured as the baseline values at the initial diagnosis before treatment. The post-treatment NLR and PLR were recorded within 7 days after the first cycles of chemotherapy. All the responses to chemotherapy were evaluated according to Response Evaluation Criteria in Solid Tumours, which was a commonly accepted standard to evaluate patient response from a certain treatment [24]. Survival status was determined from the date of last follow-up in Dec 2014. The overall survival time was defined as the time from the confirmed diagnosis of lung cancer to the date of death or to the date of last follow-up for patients who had not died before the censor date. Follow-up was done every 3 months by telephone. The contents of following up included tumour progression, recurrence, metastasis and survival days.

\section{KARGER}


Statistical methods

Continuous data were presented as the mean \pm standard deviation. Categorical data were described by the frequency and percentage. Student's t test or one-way ANOVA (Analysis of Variance) were used for continuous variables, and Fisher's exact test or $\chi 2$ test was used for comparisons of categorical data separately. SNK was used for multiple samples. ROC curve analysis was carried out to assess the prognostic ability of the PLR and NLR. The optimal cutoff values were identified as the values that maximize the You den index (sensitivity + specificity - 1) (Fig 8) [25]. The cutoff values for the NLR and PLR were 3.0 and 160 , respectively. Survival curves were estimated with the Kaplan-Meier method. The associations of the NLR and PLR with survival were evaluated in univariable and multivariable Cox regression models. In the multivariable model, all variables with a statistically significant univariate association were included. HRs and 95\% CIs were provided for univariable and multivariable Cox regression models. A Cox proportional hazards model was fitted to all individual prognostic variables to determine their independent effect. Analyses were performed in SPSS 21.0 software.

\section{Results}

\section{Population characteristics}

The clinical characteristics of the population are summarized in Table 1. A total of 934 patients were eligible for analysis between 2008 and 2014. The median age of the subjects was 60 (24-89 years); 634 of the participations were male $(67.9 \%)$ and 300 were female $(32.1 \%)$. The majority of patients were current or ex-smokers $(\mathrm{n}=514,55.0 \%)$. Information about treatment was also collected; 639 of 934 patients had received chemotherapy with a median survival time of 24 months. Clinical response was evaluated after two or three cycles of chemotherapy. Among 639 patients, $442(69.1 \%)$ obtained at least a partial response. Patients with TKI therapy represented a proportion of $4.7 \%$ in 892 with a median OS of 28 months. The 5 -year survival rate was $66.8 \%$ in patients with surgery. The median survival time in all patients was 26.31 months with a follow-up time of 5 years.

Association of the pretreatment NLR and PLR with baseline clinical characteristics in lung cancer

Correlations between the pretreatment NLR and PLR and clinical characteristics are shown in Table 2 . Females, patients who never smoked and patients with adenocarcinoma were more abundant in the lower NLR group compared with the higher group. A high NLR was associated with unfavourable tumour characteristics, including late tumour stage and a poor response to
Table 1. Baseline characteristics of patients. $\neq:$ Mortality in patients with surgery was less than $50 \%$, so median survival time could not be calculated. SCC: squamous cell carcinoma; AC: adenocarcinoma; SCLC: small cell lung cancer; CR: complete response; PR: partial response; SD: stable disease; PD: progressive disease; TKI: Tyrosine kinase inhibitor; OS: overall survival

\begin{tabular}{|c|c|}
\hline Variables & Number of patients (\%) \\
\hline Age (range), years $(n=934)$ & $60(24-89)$ \\
\hline \multicolumn{2}{|l|}{$\operatorname{Sex}(n=934)$} \\
\hline Male & $634(67.9 \%)$ \\
\hline Female & $300(32.1 \%)$ \\
\hline \multicolumn{2}{|l|}{ Smoking status $(n=934)$} \\
\hline Never smoking & $420(45.0 \%)$ \\
\hline Current or ex-smoker & $514(55.0 \%)$ \\
\hline \multicolumn{2}{|l|}{ Stage $(n=888)$} \\
\hline I & $97(10.9 \%)$ \\
\hline II & $87(9.8 \%)$ \\
\hline III & $255(28.7 \%)$ \\
\hline IV & $449(50.6 \%)$ \\
\hline \multicolumn{2}{|l|}{ Histology $(n=934)$} \\
\hline $\mathrm{AC}$ & $490(52.5 \%)$ \\
\hline SCC & $240(25.7 \%)$ \\
\hline SCLC & $153(16.4 \%)$ \\
\hline Other & $51(5.5 \%)$ \\
\hline \multicolumn{2}{|l|}{ Chemotherapy $(n=934)$} \\
\hline Yes & $639(68.4 \%)$ \\
\hline No & $295(31.6 \%)$ \\
\hline \multicolumn{2}{|c|}{ Response for initial chemotherapy ( $\mathrm{n}=639)$} \\
\hline $\mathrm{CR}$ & $153(23.9 \%)$ \\
\hline PR & $161(25.2 \%)$ \\
\hline SD & $128(20.0 \%)$ \\
\hline PD & $197(30.8 \%)$ \\
\hline \multicolumn{2}{|l|}{ TKI therapy $(\mathrm{n}=892)$} \\
\hline Yes & $42(4.7 \%)$ \\
\hline No & $850(95.3 \%)$ \\
\hline \multicolumn{2}{|l|}{ Surgery $(n=934)$} \\
\hline Yes & $278(29.7 \%)$ \\
\hline No & $656(70.3 \%)$ \\
\hline \multicolumn{2}{|l|}{ Survival time $(\mathrm{n}=934)$} \\
\hline Median OS (range) & 26.31 \\
\hline Median OS for & 24 \\
\hline Chemotherapy & 24 \\
\hline Median OS for Surgery & 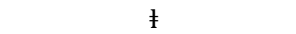 \\
\hline Median OS for TKI & $28(0-67)$ \\
\hline
\end{tabular}


chemotherapy (all $\mathrm{p}<0.01$, Table 2). The values of the pretreatment PLR were also associated with the stageand response to chemotherapy. Furthermore, the pretreatment NLR and PLR were positively correlated with the post-chemotherapy NLR and PLR.

\section{Comparison of the} NLR and PLR among different treatments and disease statuses

The values of the NLR and PLR were estimated according to treatment status (Fig 1). The values of the pretreatment NLR and PLR were 4.01 \pm 3.35 and $158.55 \pm 112.22$, respectively, which were significantly increased after surgery (NLR: 11.36 \pm 8.73 , PLR: $195.78 \pm 105.73$ ) at one week and after one cycle of chemotherapy (NLR: 5.59 $\pm 9.28, \quad$ PLR: $200.34 \pm 198.84$ )

(all $\mathrm{p}<0.001)$. There was no significant difference between the PLR of postsurgery and chemotherapy $(\mathrm{p}=0.685)$.

Furthermore, among patients who received chemotherapy, cases with a lower NLR had significantly better complete response rates (30.6\%) versus those with a higher NLR (17.1\%, p<0.001, Table 2). The values of the NLR and PLR for both pretreatment and post-chemotherapy in the CR-group were reduced compared with patients with a moderate or poor response (all $p<0.05$, Table 3 ). The NLR and PLR were sustained in patients who obtained a complete response after two or three cycles of chemotherapy ( $p>0.05)$; in patients with a moderate or poor response, the post-chemotherapy NLR and PLR were dramatically increased compared with pretreatment (all $p<0.001$, Fig 2).
Table 2. Association of pretreatment NLR/PLR with baseline clinical characteristics in lung cancer. *: $\mathrm{p}<0.05$ is significant pNLR: NLR of pretreatment; pPLR: PLR of pretreatment

\begin{tabular}{|c|c|c|c|c|c|c|}
\hline Variables & $\begin{array}{l}\text { pNLR<3 } \\
(\mathrm{n}=439)\end{array}$ & $\begin{array}{l}\mathrm{pNLR} \geq 3 \\
(\mathrm{n}=495)\end{array}$ & $\mathrm{P}$ & $\begin{array}{c}\mathrm{pPLR}<160 \\
(\mathrm{n}=589)\end{array}$ & $\begin{array}{c}\text { pPLR } \geq 160 \\
(\mathrm{n}=345)\end{array}$ & $P$ \\
\hline \multicolumn{3}{|l|}{ Age, years $(n=934)$} & 0.442 & & & 0.745 \\
\hline$<60$ & $208(47.4)$ & $247(445)$ & & $286(48.3)$ & $160(49.4)$ & \\
\hline$\geq 60$ & $231(52.6)$ & $248(50.1)$ & & $306(51.7)$ & $173(50.6)$ & \\
\hline \multicolumn{3}{|l|}{$\operatorname{Sex}(n=934)$} & $<0.001^{*}$ & & & 0.245 \\
\hline Male & $265(60.4)$ & $369(74.5)$ & & $410(69.6)$ & $224(64.9)$ & \\
\hline Female & $174(39.6)$ & $126(25.5)$ & & $182(30.7)$ & $118(34.5)$ & \\
\hline \multicolumn{3}{|l|}{ Smoking status $(\mathrm{n}=934)$} & $0.002 *$ & & & 0.725 \\
\hline Never smoking & $220(50.1)$ & $199(40.2)$ & & $263(44.4)$ & $156(45.6)$ & \\
\hline Current or ex-smoker & $219(49.9)$ & $296(59.8)$ & & $329(55.9)$ & $186(53.9)$ & \\
\hline \multicolumn{3}{|l|}{ Stage $(n=888)$} & $<0.001^{*}$ & & & $<0.001^{*}$ \\
\hline I & $63(15.1)$ & $34(7.2)$ & & $79(14.2)$ & $18(10.9)$ & \\
\hline II & $45(10.8)$ & $42(8.9)$ & & $64(11.4)$ & $87(9.8)$ & \\
\hline III & $124(29.7)$ & $130(27.7)$ & & $163(29.0)$ & $91(28.0)$ & \\
\hline IV & $186(44.5)$ & $264(56.2)$ & & $257(45.6)$ & $193(59.4)$ & \\
\hline \multicolumn{3}{|l|}{ Histology $(\mathrm{n}=934)$} & $<0.001^{*}$ & & & 0.171 \\
\hline $\mathrm{AC}$ & $262(59.7)$ & $228(46.1)$ & & $325(54.9)$ & $165(48.2)$ & \\
\hline SCC & $80(18.2)$ & $160(32.3)$ & & $138(23.4)$ & $102(29.6)$ & \\
\hline Other & $24(5.5)$ & $27(5.4)$ & & $34(5.8)$ & $17(4.9)$ & \\
\hline SCLC & $73(16.6)$ & $80(16.2)$ & & $95(16.0)$ & $58(17.0)$ & \\
\hline \multicolumn{3}{|c|}{ Post-chemotherapy NLR (n=290) } & $<0.001^{*}$ & & & $0.025^{*}$ \\
\hline$<3$ & $68(53.5)$ & $43(26.4)$ & & $78(43.3)$ & $33(30)$ & \\
\hline$\geq 3$ & $59(46.5)$ & $120(73.6)$ & & $102(56.7)$ & $77(70)$ & \\
\hline \multicolumn{3}{|c|}{ Post-chemotherapy PLR ( $\mathrm{n}=290$ ) } & $<0.001^{*}$ & & & $<0.001^{*}$ \\
\hline$<160$ & $81(63.8)$ & $63(38.7)$ & & $117(65.0)$ & $27(24.5)$ & \\
\hline$\geq 160$ & $46(36.2)$ & $100(61.3)$ & & $63(35.0)$ & $83(75.5)$ & \\
\hline \multicolumn{3}{|c|}{ Response for initial chemotherapy $(n=639)$} & $<0.001^{*}$ & & & $<0.001^{*}$ \\
\hline $\mathrm{CR}$ & $99(30.6)$ & $54(17.1)$ & & $124(29.7)$ & $29(13.7)$ & \\
\hline PR & $73(22.5)$ & $88(27.9)$ & & $85(20.3)$ & $76(34.4)$ & \\
\hline SD & $72(22.2)$ & $56(17.8)$ & & $90(21.5)$ & $38(17.2)$ & \\
\hline PD & $80(24.7)$ & $117(37.1)$ & & $119(28.5)$ & $78(35.3)$ & \\
\hline
\end{tabular}

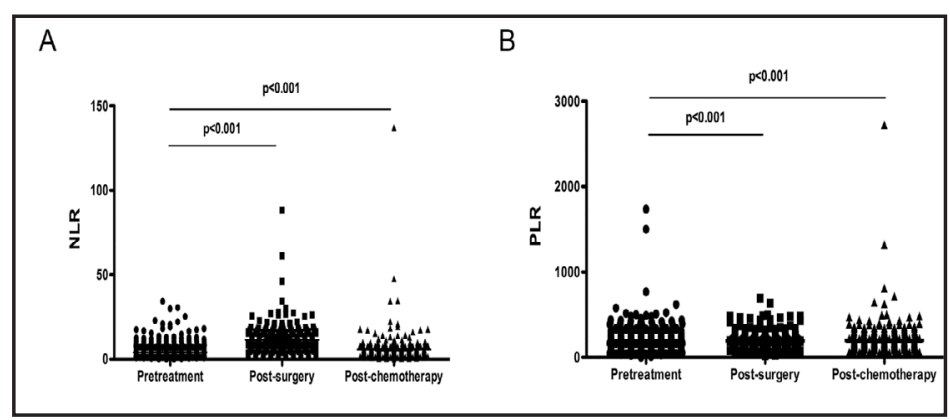

Fig. 1. The values of NLR and PLR were estimated according to treatment status. The pretreatment NLR (A) and PLR (B) were significantly increased after operation in one week and after one cycle of chemotherapy.

Table 3. Comparison of NLR and PLR among patients with different response for initial chemotherapy $\quad *$ : $\mathrm{p}<0.05$ is significant $\mathrm{CR}$ : complete response; PR, Partial response; SD: Stable disease; PD: progressive disease

\begin{tabular}{ccccccc}
\hline & & At diagnosis & \multicolumn{3}{c}{ After one cycle of chemotherapy } \\
\hline & CR & PR+SD+PD & P & CR & PR+SD+PD & P \\
NLR & $3.07 \pm 1.39$ & $3.99 \pm 3.19$ & $0.004^{*}$ & $3.05 \pm 1.69$ & $5.39 \pm 5.01$ & $0.014^{*}$ \\
PLR & $148.12 \pm .78 .00$ & $160.75 \pm 93.12$ & $<0.001^{*}$ & $148.50 \pm 74.12$ & $202.4 \pm 138.75$ & $0.042^{*}$ \\
\hline
\end{tabular}


Association of the NLR and PLR with prognosis in all patients with lung cancer

In all patients, a lower level of pretreatment NLR and PLR conferred a favourable prognosis in the univariate survival analysis (all $\mathrm{p}<0.001$, Table 4, Fig 3). Furthermore, age, smoking status, stage, surgery and chemotherapy were significant prognostic factors for OS. The patients receiving TKI treatment seemed not show a significant difference compared with other patients. But due to the limitation of the patients we included in, the results should be treated with cautions. The multivariate Cox regression analysis also identified the NLR as an independent prognostic factor, except smoking status, stage, chemotherapy and surgery (all $\mathrm{p}<0.05$, Table 4). The pretreatment PLR, however, did not reach statistical significance by the multivariate Cox analysis.

We also did some extra analysis of the current data and provided these result. As for histology, the patients with adenocarcinoma (AC) showed worse OS in highNLR group at diagnosis (Fig $4 \mathrm{~B})$. In addition, the patients with higher NLR in small cell lung cancer (SCLC) and AC showed worse OS compared with patients with lower ones after one cycle of chemotherapy (Fig 4E, Fig. 4F).

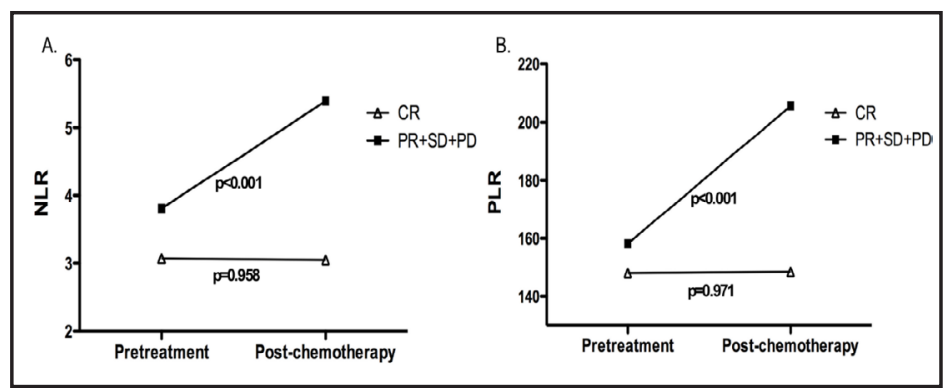

Fig. 2. The dynamic change of NLR and PLR during chemotherapy in patients with different response. NLR (A) /PLR (B) were sustained in patients obtained complete response (CR) after two or three cycles of chemotherapy, while in patients with moderate or poor response $(\mathrm{PR}+\mathrm{SD}+\mathrm{PD})$, the post-chemotherapy NLR and PLR were dramatically increased.

Table 4. Univariate and multivariate survival analysis in relation to OS in all patients with lung cancer. $*$ : $p<0.05$ is significant

\begin{tabular}{|c|c|c|c|}
\hline \multirow[b]{2}{*}{ Variables } & \multirow{2}{*}{$\begin{array}{c}\text { Univariate } \\
\mathrm{HR}, 95 \% \mathrm{CI}\end{array}$} & \multicolumn{2}{|c|}{ Multivariate } \\
\hline & & $\mathrm{HR}, 95 \% \mathrm{CI}$ & $\mathrm{P}$ \\
\hline Age $(\geq 60$ vs. $<60)$ & $1.33(1.11-1.60)^{*}$ & $1.19(0.98-1.46)$ & 0.083 \\
\hline Sex (Female vs. Male) & $0.87(0.72-1.06)$ & & \\
\hline Smoking status (Current/ex vs. Never) & $1.24(1.03-1.48)^{*}$ & $1.25(1.03-1.51)$ & $0.027 *$ \\
\hline \multicolumn{4}{|l|}{ Stage } \\
\hline I & 1.0 & 1.0 & \\
\hline II & $1.13(0.63-2.01)$ & $1.03(0.58-1.84)$ & 0.921 \\
\hline III & $2.79(1.78-4.38)^{*}$ & $1.76(1.10-2.81)$ & $0.018^{*}$ \\
\hline IV & $3.82(2.50-5.97)^{*}$ & $1.89(1.19-3.00)$ & $0.007 *$ \\
\hline \multicolumn{4}{|l|}{ Histology } \\
\hline Other & 1.0 & & \\
\hline SCC & $0.87(0.58-1.33)$ & & \\
\hline AC & $0.91(0.61-1.36)$ & & \\
\hline SCLC & $1.04(0.68-1.61)$ & & \\
\hline Surgery (Yes vs. No) & $0.25(1.19-0.33)^{*}$ & $0.31(0.22-0.42)$ & $<0.001^{*}$ \\
\hline Chemotherapy (Yes vs. No) & $0.53(0.44-0.64)^{*}$ & $0.71(0.58-0.87)$ & $<0.001^{*}$ \\
\hline TKI (Yes vs. No) & $0.83(0.53-1.29)$ & & \\
\hline pretreatment NLR ( $\leq 3$ vs. $>3$ ) & $0.59(0.49-0.71)^{*}$ & $0.69(0.55-0.85)$ & $<0.001^{*}$ \\
\hline pretreatment PLR ( $\leq 160$ vs. $>160$ ) & $0.66(0.55-0.79)^{*}$ & $0.92(0.74-1.13)$ & 0.410 \\
\hline
\end{tabular}

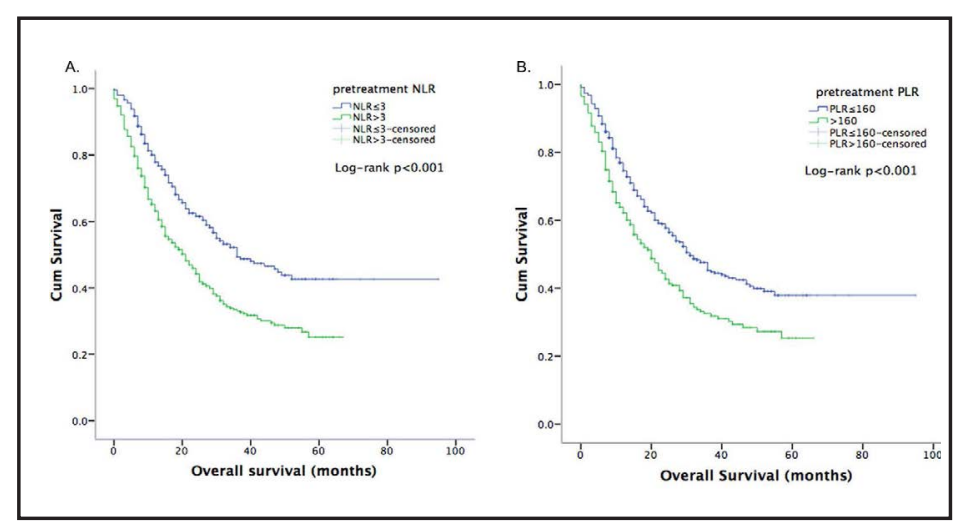

Fig. 3. Kaplan-Meier curves for OS according to pretreatment NLR and PLR in whole lung cancer patients. 
Association of the NLR and PLR with prognosis in patients received different treatment strategies

Since surgery and chemotherapy had dramatic impacts on survival in patients with lung cancer, we divided all participants into subgroups according to different treatment strategies.

For patients receiving surgery, the NLR and PLR of pretreatment were not associated with a prognosis, although patients with a higher NLR and PLR of pretreatment had trends towards poor survival after 30 months (Fig 5).

We divided patients receiving chemotherapy into subgroups according to response. In patients with disease control $(\mathrm{CR}+\mathrm{PR}+\mathrm{SD})$, age, stage, surgery, pretreatment NLR and PLR and post-chemotherapy NLR were significantly correlated with survival in the univariate analysis (Table 5). After adjustment for these factors, only a lower post-chemotherapy NLR still conferred a favourable prognosis in the multivariate analysis (Fig 6, Table 5). However, the pretreatment NLR showed no significant difference in these patients. These results indicated that the post-chemotherapy NLR had a greater impact on prognosis than the pretreatment NLR in patients who had disease control after initial chemotherapy.

A lower post-chemotherapy NLR had a trend towards an association with response to initial chemotherapy in the multivariate
Table 5. Univariate and Multivariate Cox survival analyses in relation to OS in patients obtained disease control after chemotherapy. *: p<0.05 is significant; \#: Since coefficients did not converge, no further models will be fitted

\begin{tabular}{lccc}
\hline & Univariate & Multivariate \\
\hline Variables & HR, 95\% CI & HR, 95\% CI & P \\
Age $(\geq 60$ vs. $<60)$ & $1.65(1.14-2.34)^{*}$ & $0.60(0.31-1.16)$ & 0.130 \\
Sex (Female vs. Male) & $1.00(0.68-1.48)$ & & \\
Smoking status (Current/ex vs. Never) & $1.22(0.85-1.77)$ & & \\
Stage & & & \\
$\quad$ I & 1.0 & 1.0 & \\
II & $0.90(0.35-2.32)$ & $0.82(0.09-7.54)$ & 0.862 \\
III & $2.20(1.05-4.58)^{*}$ & $0.85(0.26-2.78)$ & 0.785 \\
IV & $3.14(1.56-6.32)^{*}$ & $1.27(0.44-3.71)$ & 0.660 \\
Histology & & & \\
$\quad$ Other & 1.0 & & \\
$\quad$ SCC & $0.84(0.55-1.29)$ & & \\
$\quad$ AC & $0.63(0.23-1.78)$ & & \\
SCLC & $1.25(0.73-2.14)$ & & \\
Surgery (Yes vs. No) & $0.23(0.14-0.37)^{*} \#$ & & \\
TKI (Yes vs No) & $1.09(0.51-2.35)$ & & \\
pretreatment NLR $(\leq 3$ vs. $>3)$ & $0.62(0.43-0.89)^{*}$ & $0.83(0.41-1.66)$ & 0.589 \\
pretreatment PLR $(\leq 160$ vs. $>160)$ & $0.59(0.41-0.86)^{*}$ & $0.88(0.45-1.74)$ & 0.712 \\
post-chemotherapy NLR $(\leq 3$ vs. $>3)$ & $0.33(0.16-0.67)^{*}$ & $0.36(0.17-0.76)$ & $0.007^{*}$ \\
postchemotherapy PLR $(\leq 160$ vs. $>160)$ & $0.56(0.30-1.04)$ & & \\
\hline
\end{tabular}

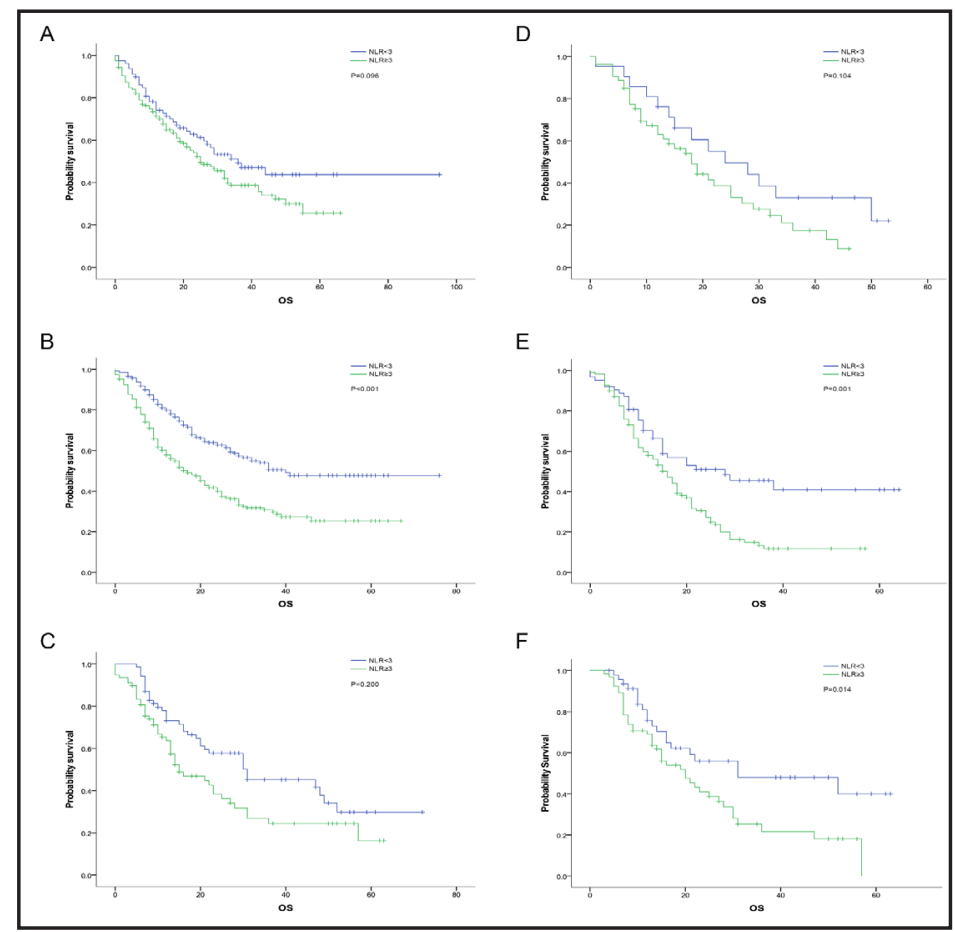

Fig. 4. Kaplan-Meier curves for overall survival according to NLR, Histology and treatment course. OS stratified according to the NLR at diagnosis in (A) SCC (NLR<3 vs NLR $\geq 3$, median OS 36 vs 25 months, $\mathrm{P}=0.096)$ (B) $\mathrm{AC}(\mathrm{NLR}<3$ vs $\mathrm{NLR} \geq 3$, median OS 40 vs 17 months, $\mathrm{P}<0.001)$ (C) SCLC $(\mathrm{NLR}<3$ vs $\mathrm{NLR} \geq 3$, median OS 31 vs 15 months, $\mathrm{P}=0.200)$. OS stratified according to the NLR after one cycle of chemotherapy in (D) SCC (NLR $<3$ vs $N L R \geq 3$, median OS 24 vs 18 months, $\mathrm{P}=0.104$ ) (E) $\mathrm{AC}(\mathrm{NLR}<3$ vs $\mathrm{NLR} \geq 3$, median OS 28 vs 16 months, $\mathrm{P}<0.001)$ (F) SCLC $(\mathrm{NLR}<3$ vs $\mathrm{NLR} \geq 3$, median OS 31 vs 20 months, $\mathrm{P}=0.014)$. Abbreviations: NLR: neutrophil-to-lymphocyte ratio; SCC: squamous cell carcinoma; AC: adenocarcinoma; SCLC: small cell lung cancer; OS: overall survival. 
logistic analysis $(\mathrm{p}=0.051$, OR, 0, 95\% CI: 0.281-1.002), providing a limited suggestion of a differential effect of chemotherapy between the two NLR groups.

\section{Analysis of dynamic change of the NLR and PLR during chemotherapy}

We observed the dynamic change of the NLR in patients under control during chemotherapy. Patients receiving chemotherapy were divided into four groups, including maintained a low NLR, maintained a high NLR, increased NLR and decreased NLR groups. The analysis revealed that patients who maintained a low NLR had the best survival (median, 56 months), whereas patients with an increased NLR had the worst OS, with a median of 24 months. With adjustments for age, stage and pretreatment PLR, a dynamic change of the NLR during chemotherapy remained an independent predictor of overall survival (HR: 0.196, 95\% CI, 0.064$0.602, p=0.004$, Fig 7). The changes in the PLR did not show a significant difference; even patients with an increased PLR had the shortest median survival time (data not shown).

\section{Discussion}

In our study, we investigated the prognostic effect of the NLR and PLR on lung cancer by a retrospective analysis of 934 patients with lung cancer. We found that the NLR and PLR were correlated with different disease status and responses to chemotherapy. A lower pretreatment NLR was independently associated with a favourable prognosis in all patients with lung cancer. In the patients with disease control after chemotherapy, a maintained low NLR during chemotherapy was identified as a predictor for favourable survival. The findings suggested that a lower NLR at diagnosis might predict a benefit from chemotherapy among all patients with lung cancer. Although the elevation of

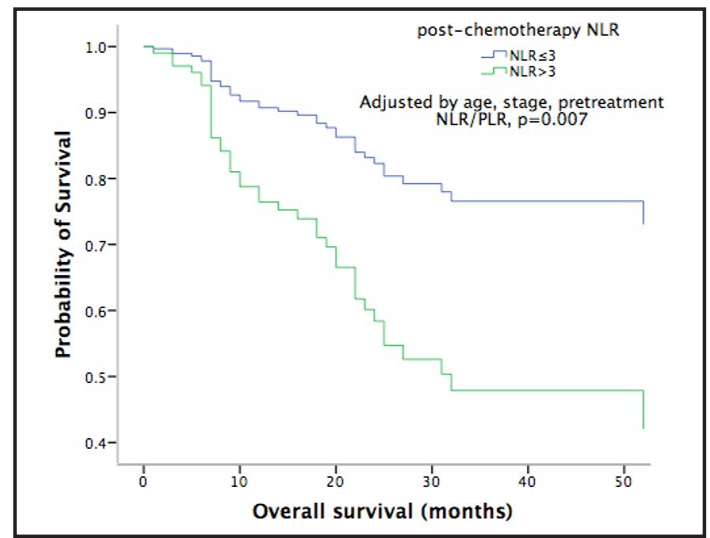

Fig. 6. Overall survival according to postchemotherapy NLR in patients obtained disease control patients (CR+PR+SD) after initial chemotherapy.

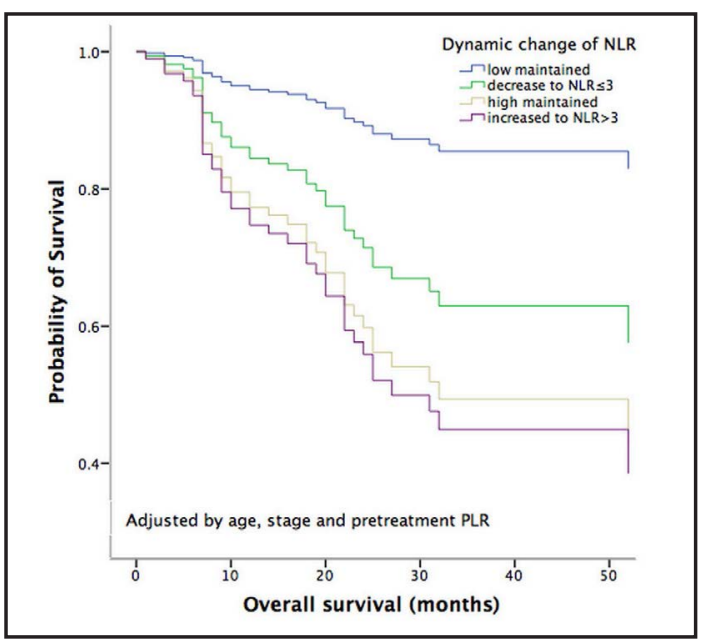

Fig. 7. Overall survival according to dynamic change of NLR during chemotherapy in patients obtained disease control patients $(\mathrm{CR}+\mathrm{PR}+\mathrm{SD})$ after initial chemotherapy. 
the pretreatment PLR was also associated with the prognosis in the univariate survival analysis, the multivariate Cox analysis showed that the PLR was not an independent prognostic indicator in the entire cohort or in any subgroups.

It is increasingly

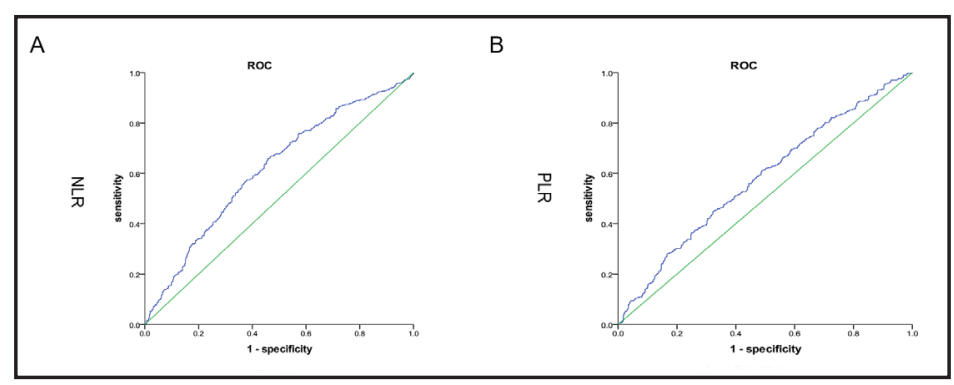

Fig. 8. The ROC curve for pretreatment NLR (A) and PLR (B). recognized that the host systemic inflammatory response plays a critical role in the development and progression of many cancers [26, 27]. An elevated NLR conferred adverse survival in gastrointestinal cancer, pancreatic cancer, breast cancer, bladder cancer and other cancers [7, 9, 28, 29]. A recent meta-analysis of 40599 patients with solid tumours showed that an NLR greater than 4.00 was associated with a substantial increase in the risk for all-cause mortality (HR: 1.81, 95\% CI: 1.67-1.97) [8]. Previous studies also demonstrated that the PLR was a prognostic factor in lung cancer. A meta-analysis including 3430 patients proved that an elevated PLR predicted poor OS and poor disease-free survival and progression-free survival in non-small cell lung cancer [30]. The prognostic value of the NLR and PLR in patients with lung cancer appears to have been established by our study and previous studies [12-22]. However, the cutoff value and prognostic effect of the NLR and PLR remain controversial. It has been reported that the optimal cutoff value for prognostic indicators could be better selected by validating previously established values from other studies. Herein, we analysed the optimal cutoff by ROC curve analysis. Based on our findings, a cutoff value of 3.0 for the NLR and 160 for the PLR were determined to distinguish between patients with a higher risk of adverse outcomes and patients with a lower risk. Furthermore, we analysed the association of the NLR and PLR with prognosis according to different cofounders. Our study confirmed the previous conclusion that the NLR is an independent prognostic factor and the PLR has little influence on prognosis after adjustments for other confounders [17, 21, 22].

The mechanism by which the NLR and PLR may impact prognosis remains unclear. The peripheral NLRs are thought to be proxies of the ongoing inflammatory process in the tumour microenvironment [7]. Several studies demonstrated that neutrophils and platelets contribute to pro-tumour activities in vivo, including enhanced angiogenesis, which promote tumour cell proliferation and the metastatic potential of tumour cells [31-33]. Meanwhile, lymphocytes have been thought to have an essential role in cancer immune surveillance and are hypothesized to suppress tumour maturation [6]. It is therefore biologically plausible that imbalances in the ratio of the peripheral neutrophils/platelets to lymphocytes may provide insight into understanding tumour progression and prognosis in individuals with cancer [7].

Systemic inflammation in patients with malignancy is considered to reflect the cytokine profile produced both by the tumour and as a component of the host response to the tumour [34]. Increased levels of systemic inflammation have been shown to correlate with worse survival and a poor response to treatment in a number of solid organ tumours $[35,36]$. As our findings showed, patients with a lower NLR had significantly better chemotherapy response versus those with a higher NLR. Both pretreatment and post-chemotherapy NLRs were closely associated with a poor response to chemotherapy. Similarly, a recently reported large retrospective series found that patients with an NLR $<3$ had significantly better tumourcontrol among patients receiving first line platinum with gemcitabine in advanced biliary tract cancer. Additionally, the post-chemotherapy NLR has a greater impact on the prognosis of patients under control in our study. The level of the NLR changed with the disease status and treatment strategies. Patients who maintained a low NLR during chemotherapy had the most favourable prognosis in patients under control, whereas patients with increased NLR 
had the shortest survival. The findings suggested that a maintained low level of NLR could be a surrogate for predicting the response to chemotherapy. Chua et al [37]. investigated a total of 162 patients with metastatic colorectal cancer who received palliative chemotherapy and reported that patients with pretreatment NLR values of $>5$ that decreased to $\leq 5$ before the second chemotherapy cycle showed a significantly longer progression-free survival and a trend towards longer OS compared with patients with a persistent NLR of $>5$. Data in patients with oesophageal and biliary cancer have also suggested an association between the NLR and response to cisplatin-based chemotherapy [38,39]. These results indicated that the NLR was predictive for the prognosis and response to chemotherapy regardless of tumour origin. The potential mechanism could be explained by the fact that the inflammation also affects the efficacy of chemotherapy drugs.

Our current study found that the pretreatment NLR and PLR were not correlated with survival in patients receiving surgery. These results are different from a previous study that demonstrated that the NLR is a prognostic biomarker in patients with early stage NSCLC undergoing surgery [13]. The difference could be because our study enrolled a larger population in the real world, including different subtypes of lung cancer and a larger proportion of patients with advanced disease. These differences may account for the different results. Unlike Kang et al [22]., we observed that the NLR and PLR level were increased dramatically after one cycle of chemotherapy, as well as before and after surgery. The distinction may be caused by different definitions of pre and after treatment of NLR and PLR.

Our research was conducted on a relatively large number of participants and confirmed the results of previous studies that showed an association between the NLR and PLR and lung cancer. We investigated the roles of the NLR and PLR at the time of pretreatment and post-treatment in patients with lung cancer. We found that the dynamic change of NLR during chemotherapy could predict the response to chemotherapy. A major advantage of our research is that detailed information on tumour characteristics and treatment were recorded, which allowed for extensive confounder adjustment. In addition, our research was the first to include all other subtypes of lung cancer in the assessment of the prognostic significance of the NLR and PLR.

There are some limitations in our research. As a retrospective study, there are several limitations inherent to the design, including the retrospective data collection. Furthermore, there are several confounding factors, such as inflammatory conditions and steroid treatments $[17,22]$. Moreover, the prognostic value of the NLR was found in many types of tumours, indicating that the NLR might not be a tumour-specific marker.

\section{Conclusion}

Our results suggested that the NLR showed a strong association with outcome, and its dynamic change may predict a benefit from chemotherapy in a retrospective analysis. These inflammation markers could be used as response indicators for different treatments and may improve patient selection. The NLR may be readily available in clinical practice as prospective stratification criteria in estimating response and assisting clinicians in evaluating patients' overall prognosis.

\section{Acknowledgements}

This study was supported by grants from the Nature Science Foundation of China (81201851) and the Sichuan province science and technology support program (2014SZ023).

(I) Conception and design: W Li, D Liu; (II) Administrative support: J Jin, D Liu; (III) Provision of study materials or patients: L Lei, J Song; (IV) Collection and assembly of data: L Lei, J Song, J Jin, Y Huang; (V) Data analysis and interpretation: J Jin, D Liu; (VI) Manuscript writing: All authors; (VII) Final approval of manuscript: All authors. 


\section{Cellular Physiology Cell Physiol Biochem 2018;46:1595-1605 \begin{tabular}{l|l} 
and Biochemistry & $\begin{array}{l}\text { DOI: 10.1159/000489207 } \\
\text { Published } 2018 \text { The Author(s). Published by S. Karger AG, Basel } \\
\text { www.karger.com/cpb }\end{array}$
\end{tabular}

Liu et al.: Neutrophil to Lymphocyte Ratio and Lung Cancer

\section{Disclosure Statement}

The authors have no conflicts of interest to declare.

\section{References}

$\rightarrow$ Siegel RL, Miller KD, Jemal A: Cancer statistics, 2015. CA Cancer J Clin 2015;65:5-29.

-2 Siegel R, DeSantis C, Virgo K, Stein K, Mariotto A, Smith T, Cooper D, Gansler T, Lerro C, Fedewa S, Lin C, Leach C, Cannady RS, Cho H, Scoppa S, Hachey M, Kirch R, Jemal A, Ward E: Cancer treatment and survivorship statistics, 2012. CA Cancer J Clin 2012;62:220-241.

-3 Hanahan D, Weinberg RA: Hallmarks of cancer: the next generation. Cell 2011;144:646-674.

-4 Lorente D, Mateo J, Templeton AJ, Zafeiriou Z, Bianchini D, Ferraldeschi R, Bahl A, Shen L, Su Z, Sartor O, de Bono JS: Baseline neutrophil-lymphocyte ratio (NLR) is associated with survival and response to treatment with second-line chemotherapy for advanced prostate cancer independent of baseline steroid use. Ann Oncol 2015;26:750-755.

5 Bambury RM, Teo MY, Power DG, Yusuf A, Murray S, Battley JE, Drake C, O’Dea P, Bermingham N, Keohane C: The association of pre-treatment neutrophil to lymphocyte ratio with overall survival in patients with glioblastoma multiforme. Journal of Neuro-Oncology 2013;114:149-154.

6 Shankaran V, Ikeda H, Bruce AT, White JM, Swanson PE, Old LJ, Schreiber RD: IFNgamma and lymphocytes prevent primary tumour development and shape tumour immunogenicity. Nature 2001;410:1107-1111.

7 Koh CH, Bhoo-Pathy N, Ng KL, Jabir RS, Tan GH, See MH, Jamaris S, Taib NA: Utility of pre-treatment neutrophil-lymphocyte ratio and platelet-lymphocyte ratio as prognostic factors in breast cancer. Br J Cancer 2015;10.1038/bjc.2015.183

-8 Templeton AJ, McNamara MG, Seruga B, Vera-Badillo FE, Aneja P, Ocana A, Leibowitz-Amit R, Sonpavde G, Knox JJ, Tran B, Tannock IF, Amir E: Prognostic role of neutrophil-to-lymphocyte ratio in solid tumors: a systematic review and meta-analysis. J Natl Cancer Inst 2014;106:dju124.

-9 Hong C, Wei Y, Jiang J, Zhao C, Liang G, Wang G, Yang H: Associations between lifestyles and neutrophillymphocyte and platelet-lymphocyte ratios in colorectal cancer. Asia Pac J Clin Oncol 2014;10:168-174.

10 Aliustaoglu M, Bilici A, Seker M, Dane F, Gocun M, Konya V, Ustaalioglu BB, Gumus M: The association of pre-treatment peripheral blood markers with survival in patients with pancreatic cancer. Hepatogastroenterology 2010;57:640-645.

11 Yodying H, Matsuda A, Miyashita M, Matsumoto S, Sakurazawa N, Yamada M, Uchida E: Prognostic Significance of Neutrophil-to-Lymphocyte Ratio and Platelet-to-Lymphocyte Ratio in Oncologic Outcomes of Esophageal Cancer: A Systematic Review and Meta-analysis. Annals of Surgical Oncology 2016;23:1-9.

12 Wu Y, Chen Y, Yang X, Chen L, Yang Y: Neutrophil-to-lymphocyte ratio (NLR) and platelet-to-lymphocyte ratio (PLR) were associated with disease activity in patients with systemic lupus erythematosus. International Immunopharmacology 2016;36:94-99.

13 Lan H, Zhou L, Chi D, Zhou Q, Tang X, Zhu D, Yue J, Liu B: Preoperative platelet to lymphocyte and neutrophil to lymphocyte ratios are independent prognostic factors for patients undergoing lung cancer radical surgery: A single institutional cohort study. Oncotarget 2016;

14 Zhang T, Jiang Y, Qu X, Shen H, Liu Q, Du J: Evaluation of preoperative hematologic markers as prognostic factors and establishment of novel risk stratification in resected pN0 non-small-cell lung cancer. PLoS One 2014;9:e111494.

15 Zhou DS, Xu L, Luo YL, He FY, Huang JT, Zhang YJ, Chen MS: Inflammation scores predict survival for hepatitis B virus-related hepatocellular carcinoma patients after transarterial chemoembolization. World J Gastroenterol 2015;21:5582-5590.

16 Wang X, Teng F, Kong L, Yu J: Pretreatment neutrophil-to-lymphocyte ratio as a survival predictor for smallcell lung cancer. Onco Targets Ther 2016;9:5761-5770.

17 Unal D, Eroglu C, Kurtul N, Oguz A, Tasdemir A: Are Neutrophil/Lymphocyte and Platelet/Lymphocyte Rates in Patients with Non-Small Cell Lung Cancer Associated with Treatment Response and Prognosis? Asian Pacific Journal of Cancer Prevention 2013;14:5237-5242.

18 Pinato DJ, Shiner RJ, Seckl MJ, Stebbing J, Sharma R, Mauri FA: Prognostic performance of inflammationbased prognostic indices in primary operable non-small cell lung cancer. Br J Cancer 2014;110:1930-1935. 


\section{Cellular Physiology Cell Physiol Biochem 2018;46:1595-1605 \begin{tabular}{l|l} 
and Biochemistry & $\begin{array}{l}\text { DOI: 10.1159/000489207 } \\
\text { Published } 2018 \text { The Author(s). Published by S. Karger AG, Basel } \\
\text { www.karger.com/cpb }\end{array}$
\end{tabular}

Liu et al.: Neutrophil to Lymphocyte Ratio and Lung Cancer

19 Sanchez-Salcedo P, de-Torres JP, Martinez-Urbistondo D, Gonzalez-Gutierrez J, Berto J, Campo A, Alcaide AB, Zulueta JJ: The neutrophil to lymphocyte and platelet to lymphocyte ratios as biomarkers for lung cancer development. Lung Cancer 2016;97:28-34.

-20 Kos M, Hocazade C, Kos FT, Uncu D, Karakas E, Dogan M, Uncu HG, Yildirim N, Zengin N: Prognostic role of pretreatment platelet/lymphocyte ratio in patients with non-small cell lung cancer. Wien Klin Wochenschr 2016;128:635-640.

21 Wu G, Yao Y, Bai C, Zeng J, Shi D, Gu X, Shi X, Song Y: Combination of platelet to lymphocyte ratio and neutrophil to lymphocyte ratio is a useful prognostic factor in advanced non-small cell lung cancer patients. Thorac Cancer 2015;6:275-287.

-22 Kang MH, Go SI, Song HN, Lee A, Kim SH, Kang JH, Jeong BK, Kang KM, Ling H, Lee GW: The prognostic impact of the neutrophil-to-lymphocyte ratio in patients with small-cell lung cancer. Br J Cancer 2014;111:452-460.

23 Edge SB, Compton CC: The American Joint Committee on Cancer: the 7th edition of the AJCC cancer staging manual and the future of TNM. Ann Surg Oncol 2010;17:1471-1474.

-24 Eisenhauer EA, Therasse P, Bogaerts J, Schwartz LH, Sargent D, Ford R, Dancey J, Arbuck S, Gwyther S, Mooney M, Rubinstein L, Shankar L, Dodd L, Kaplan R, Lacombe D, Verweij J: New response evaluation criteria in solid tumours: revised RECIST guideline (version 1.1). Eur J Cancer 2009;45:228-247.

25 Lai CY, Tian L, Schisterman EF: Exact confidence interval estimation for the Youden index and its corresponding optimal cut-point. Comput Stat Data Anal 2012;56:1103-1114.

-26 Gioulbasanis I, Pallis A, Vlachostergios PJ, Xyrafas A, Giannousi Z, Perdikouri IE, Makridou M, Kakalou D, Georgoulias V: The Glasgow Prognostic Score (GPS) predicts toxicity and efficacy in platinum-based treated patients with metastatic lung cancer. Lung Cancer 2012;77:383-388.

27 McMillan DC: The systemic inflammation-based Glasgow Prognostic Score: a decade of experience in patients with cancer. Cancer Treat Rev 2013;39:534-540.

-28 Aliustaoglu M, Bilici A, Seker M, Dane F, Gocun M, Konya V, Ustaalioglu BB, Gumus M: The association of pre-treatment peripheral blood markers with survival in patients with pancreatic cancer. Hepatogastroenterology 2010;57:640-645.

-29 Wei Y, Jiang YZ, Qian WH: Prognostic role of NLR in urinary cancers: a meta-analysis. PLoS One 2014;9:e92079.

-30 Gu X, Sun S, Gao XS, Xiong W, Qin S, Qi X, Ma M, Li X, Zhou D, Wang W, Yu H: Prognostic value of platelet to lymphocyte ratio in non-small cell lung cancer: evidence from 3, 430 patients. Sci Rep 2016;6:23893.

31 Coussens LM, Werb Z: Inflammation and cancer. Nature 2002;420:860-867.

-32 De Larco JE, Wuertz BR, Furcht LT: The potential role of neutrophils in promoting the metastatic phenotype of tumors releasing interleukin-8. Clin Cancer Res 2004;10:4895-4900.

33 Bambace NM, Holmes CE: The platelet contribution to cancer progression. J Thromb Haemost 2011;9:237249.

-34 Hooper CE, Lyburn ID, Searle J, Darby M, Hall T, Hall D, Morley A, White P, Rahman NM, De Winton E, Clive A, Masani V, Arnold DT, Dangoor A, Guglani S, Jankowska P, Lowndes SA, Harvey JE, Braybrooke JP, Maskell NA: The South West Area Mesothelioma and Pemetrexed trial: a multicentre prospective observational study evaluating novel markers of chemotherapy response and prognostication. Br J Cancer 2015;112:11751182.

-35 Proctor MJ, Morrison DS, Talwar D, Balmer SM, Fletcher CD, O’Reilly DS, Foulis AK, Horgan PG, McMillan DC: A comparison of inflammation-based prognostic scores in patients with cancer. A Glasgow Inflammation Outcome Study. Eur J Cancer 2011;47:2633-2641.

-36 Roxburgh CS, McMillan DC: Role of systemic inflammatory response in predicting survival in patients with primary operable cancer. Future Oncol 2010;6:149-163.

37 Chua W, Charles KA, Baracos VE, Clarke SJ: Neutrophil/lymphocyte ratio predicts chemotherapy outcomes in patients with advanced colorectal cancer. Br J Cancer 2011;104:1288-1295.

-38 Sato H, Tsubosa Y, Kawano T: Correlation between the pretherapeutic neutrophil to lymphocyte ratio and the pathologic response to neoadjuvant chemotherapy in patients with advanced esophageal cancer. World J Surg 2012;36:617-622.

-39 Grenader T, Nash S, Plotkin Y, Furuse J, Mizuno N, Okusaka T, Wasan H, Valle J, Bridgewater J: Derived Neutrophil Lymphocyte Ratio may predict benefit from Cisplatin in the Advanced Biliary Cancer: The ABC02 and BT-22 studies. Ann Oncol 2015;10.1093/annonc/mdv253 